\title{
Home is where the future is: The BrightFocus Foundation consensus panel on dementia care
}

\author{
Quincy M. Samus ${ }^{\mathrm{a}, *}$, Betty Smith Black ${ }^{\mathrm{a}}$, Diane Bovenkamp ${ }^{\mathrm{b}}$, Michael Buckley ${ }^{\mathrm{b}}$, \\ Christopher Callahan ${ }^{\mathrm{c}}$, Karen Davis ${ }^{\mathrm{d}}$, Laura N. Gitlin ${ }^{\mathrm{e}}$, Nancy Hodgson ${ }^{\mathrm{f}}$, Deirdre Johnston ${ }^{\mathrm{a}}$, \\ Helen C. Kales ${ }^{\mathrm{g}, \mathrm{h}}$, Michele Karel ${ }^{\mathrm{i}}$, John Jay Kenney ${ }^{j}$, Shari M. Ling ${ }^{\mathrm{k}}$, Maï Panchal, ${ }^{1, \mathrm{~m}, \mathrm{n}}$, \\ Melissa Reuland ${ }^{\mathrm{a}}$, Amber Willink ${ }^{\mathrm{d}}$, Constantine G. Lyketsos ${ }^{\mathrm{a}}$ \\ ${ }^{a}$ Department of Psychiatry, School of Medicine, Johns Hopkins University, Baltimore, MD, USA \\ ${ }^{b}$ BrightFocus Foundation, Clarksburg, MD, USA \\ ${ }^{c}$ Department of Medicine, Indiana University School of Medicine, Center for Aging Research, Indianapolis, IN, USA \\ ${ }^{d}$ Department of Health Policy and Management, Bloomberg School of Public Health, Johns Hopkins University, Baltimore, MD, USA \\ ${ }^{e}$ Department of Community Public Health, Johns Hopkins University School of Nursing, Baltimore, MD, USA \\ ${ }^{f}$ Department of Gerontology, School of Nursing, University of Pennsylvania, Philadelphia, PA, USA \\ ${ }^{g}$ Department of Psychiatry, University of Michigan, Ann Arbor, MI, USA \\ ${ }^{h}$ Department of Veterans Affairs, HSR\&D Center for Clinical Management Research, Washington, DC, USA \\ ${ }^{i}$ Veterans Administration Central Office, Washington, DC, USA \\ ${ }^{j}$ Aging \& Disability Services, Montgomery Department of Health \& Human Services, Rockville, MD, USA \\ ${ }^{k}$ Center for Clinical Standards and Quality, Centers for Medicare and Medicaid Services, Baltimore, MD, USA \\ ${ }^{l}$ Fondation Vaincre Alzheimer, Paris, France \\ ${ }^{m}$ Alzheimer Forschung Initiative, Düsseldorf, Germany \\ ${ }^{n}$ Alzheimer Nederland, Amersfoort, Amersfoort, The Netherlands
}

\begin{abstract}
Introduction: A national consensus panel was convened to develop recommendations on future directions for home-based dementia care (HBDC).

Methods: The panel summarized advantages and challenges of shifting to HBDC as the nexus of care and developed consensus-based recommendations.

Results: The panel developed five core recommendations: (1) HBDC should be considered the nexus of new dementia models, from diagnosis to end of life in dementia; (2) new payment models are needed to support HBDC and reward integration of care; (3) a diverse new workforce that spans the care continuum should be prepared urgently; (4) new technologies to promote communication, monitoring/safety, and symptoms management must be tested, integrated, and deployed; and (5) targeted dissemination efforts for HBDC must be employed.

Discussion: HBDC represents a promising paradigm shift to improve care for those living with dementia and their family caregivers: these recommendations provide a framework to chart a course forward for HBDC.

(C) 2017 the Alzheimer's Association. Published by Elsevier Inc. All rights reserved.
\end{abstract}

Keywords: $\quad$ Alzheimer's and related dementias (ADRD); Dementia; Home-based care; Community-based care; Workforce; Technology; Cost effectiveness; Payment models; Care financing

*Corresponding author. Tel.: 410-550-6493; Fax: 410-550-1407.

E-mail address: qmiles@jhmi.edu

\section{Purpose and description of consensus panel}

This report presents findings and recommendations of a national consensus panel (Panel) convened by the Johns Hopkins Translational Aging Services Core in the 
Department of Psychiatry and Behavioral Sciences with support from the "BrightFocus" Foundation. The purpose of the Panel was to draw attention to the overwhelming service burden that dementia and family caregiving will pose in the future, to focus on home-based dementia care (HBDC) as a critical component of care services for people with Alzheimer's disease and related dementias in the coming decades, and to impact the field by disseminating concrete recommendations for future directions in HBDC. Specifically, the Panel reviewed key issues, barriers, and opportunities relating to payment and care financing; evidence-based research, dissemination, workforce, and technology.

The multidisciplinary expert panel consists of 15 nationally recognized clinicians, researchers, health economists, advocates, policy makers, and health services administrators from diverse organizations (e.g. Johns Hopkins University Schools of Medicine, Nursing, Public Health, Hopkins; Indiana University; University of Pennsylvania; University of Michigan; Veterans Administration; Maryland Department of Health \& Human Services; Centers for Medicare and Medicaid Services; LECMA, AFi, and iSAO France) and disciplines (e.g., psychology, sociology, economics, health care administration, neuroscience, geriatrics, psychiatry, gerontology, and nursing).

The Panel regularly met by teleconference (four meetings), supplemented by email communications, over an 18month period, and convened for one in-person full day meeting (December 2015). The full day meeting, which was recorded and dictated by a professional science writer, included a series of six presentations by Panel members, each followed by a full group discussion to develop recommendations. Recommendations were further refined through subsequent teleconferences and email communications. While the Panel implemented a semi-structured format for identification of important topic areas, facilitation of discussions on each topic, and agreement on recommendations by the Consensus members, the Panel did not employ formal consensus classification techniques like the Delphi Method. Preliminary and abbreviated Panel findings have been presented previously at the Alzheimer's Association International Conference, the Patient Centered Outcomes Research Institute pre-Research summit meeting, and the $2017 \mathrm{Na}$ tional Research Summit on Care, Services and Supports for Persons with Dementia and Their Caregivers which will inform the U.S. National Alzheimer's Plan Project.

In this article, we discuss dementia care across the long-term care services continuum, define HBDC, provide a rationale for shifting the dementia care paradigm to the home, discuss the relative advantages and challenges of a home-based approach, and put forth a set of key consensus-based recommendations for moving forward with a robust and evidence-based approach to HBDC in an era of health care reform.

\section{Toward optimal dementia care across the continuum}

There is a critical and urgent need to provide higher quality and lower cost services to persons with dementia. There are an estimated 46.8 million persons living with dementia worldwide, and this number will nearly double every 20 years to a projected estimate of 131.5 million in 2050. Dementia prevalence estimates for persons aged 60 and older range between $4.6 \%$ (Central Europe) to 8.7\% (North Africa and the Middle East), with most regional rates falling between 5.6 and $7.6 \%$. Projections suggest that low- to middle-income countries will experience disproportionately high increases prevalence rates, increasing from accounting for $58 \%$ of all global dementia cases in 2015 to $68 \%$ in 2050 [1].

In the United States, of the estimated 5.4 million Americans living with dementia, unpaid family caregivers typically provide the lion's share of dementia care, with millions of American family members providing care to home-dwelling family members or friends with dementia $[2,3]$. Over the trajectory of the illness, it is common for persons with dementia to have health care encounters and receive services in a variety of settings including outpatient clinics, inpatient hospitals, rehabilitation units, behavioral health-focused medical units, nursing facilities, assisted living, and hospice facilities. In fact, among users of long-term services in the United States, national estimates suggest the prevalence of diagnosed dementia is $50 \%$ in nursing homes residents, $45 \%$ among hospice patients, and $31 \%$ among home health agency patients [4]. For assisted living, national estimates suggest that about $70 \%$, or 7 of 10 residents, have some form of cognitive impairment [5]. International studies of the prevalence of dementia in longterm care homes show similar trends [6]. Importantly, however, at any given time, most living with dementia are cared for at home. About two-thirds of the 5.4 million Americans with dementia, are not in acute, post-acute, or long-term residential settings but are instead living in their own homes in the community. The proportion cared for at home is even greater, about $94 \%$, in low- and middle-income countries that have very fewer care and support resources [1].

Care for persons with dementia is complex due to a relative lack of condition-specific continuity and coordination across care settings, inadequate care in the outpatient arena, limitations in provider education, time and resources, and lack of financial alignment and incentives. Thus in the context of the considerable health system fragmentation and poor coordination within and between health care and communitybased support systems, dementia care is rarely delivered as a comprehensive set of services [7]. These factors can lead to potentially preventable emergency department visits, inpatient hospitalizations, and premature institutionalizations $[8,9]$. Often, even receipt of a timely diagnosis, which is absent about half of the time [10], presents a major barrier to entering or accessing dementia-focused care and support services. Further, social and supportive services, critical to meeting dementia-related care needs, are fragmented and often not reimbursed through health insurance [11]. As a consequence, many persons with dementia and their family caregivers have needs that go unmet [12-14]. Common unmet needs of persons with dementia include timely 
recognition and evaluation, general medical care, safety (e.g., home safety and driving), activities of daily living (ADL) support, activities, behavioral management, and environmental needs [12-19]. Caregivers, who are critical factors in the equation, often lack emotional support, respite time, disease education, and care for their own mental health and medical needs, and key services to meet these needs are often underutilized, not locally available, too expensive, or not accessible $[13,14,20]$. These unmet needs, particularly caregiver burden, falls and acute medical problems, behavioral symptoms exacerbate poor outcomes and increase risk for costly institutionalization [21-23].

Although curative dementia treatment development is ongoing, the reality is that it will be some time before effective disease modifying treatments are available. Comprehensive and effective dementia management interventions must be widely implemented to care for those affected now and in the foreseeable future. Optimal "dementia care across the continuum" involves putting in place proven, person- and family-centered interdisciplinary interventions to maximize quality of life and minimize complications; maintaining this support and guidance through the course of the illness as the needs of both the person with dementia and the caregiver change; and, successfully connecting medical, social, and supportive care professionals, workers, and informal caregivers over the course of the illness to achieve patientcentered outcomes in the care delivery and transitions between care settings. Because of the unique needs or vulnerabilities of the person with dementia and caregivers and heightened use of a variety of care services and settings, it is particularly important to focus on communication, coordination, and connection between providers, informal caregivers, and others involved in care. Proactive coordinated dementia care and caregiver support, including highquality primary care, is associated with fewer health care encounters and transitions (emergency department visits, hospitalizations) [9], can improve quality of life and function in dementia [24-26], delay placement in long-term care, and improve caregiver outcomes [27,28] and is supported by practice recommendations [29]. The best outcomes are associated with comprehensive person- and family-centered services that are timely, responsive, flexible, and tailored to individual need. These principles of quality care align with the goals of global action plans to address the challenges that dementia poses worldwide [30].

\section{Home is where the future is}

"Home-based dementia care should be considered the nexus of new long term care models."

We posit that the home, rather than outpatient, inpatient or long-term care settings, is the most important care setting and should serve as the nexus of dementia care as we move forward with dementia health policy planning and health care reform to improve care and efficiency.
From a public health perspective, optimizing dementia care in the home to reduce or delay transitions to other care settings may provide the maximum population-level benefit and is desirable given the overwhelming preference of older people to remain in their homes and familiar communities for as long as possible [31], the huge economic costs associated with acute health care use and premature long-term institutionalization [32,33], as well as evidence to suggest that it is associated with higher quality of life compared with nursing homes [34]. HBDC can be defined as care and support provided to a person with dementia in his/her own home by informal caregivers (family, friends, neighbors, and fictive kin) and formal caregivers (health professionals and community workers), using a range of assistive technologies to meet medical, psychosocial, functional, behavioral, spiritual, material, safety, and environmental needs. Basic principles guiding comprehensive HBDC are listed in Table 1.

A number of converging societal trends support the emphasis on the home as the nexus for dementia care: (1) the current and projected prevalence of disease with uncertainty about the emergence of "curative" treatments for dementia in the near future, (2) anticipation emergent treatments may prolong the duration of dementia, thus increasing its point-prevalence as well as longer period of time needing care, (3) the desire of older persons with dementia and their families to remain at home, (4) the recognition that persons with dementia have social, environmental, emotional, safety, and support care needs that go beyond medical care and services, (5) the need to reduce health care costs [10] and improve quality of care by shifting care from traditional, institutional long-term care to home and community-based options [35], (6) the mismatch between institutional long-term care supply and need for long-term care services, and (7) the shrinking pool of family caregivers available to provide care and the potential numbers of people who will require care.

Focusing on the home as the nexus of dementia care has several advantages. From a conceptual standpoint, providing HBDC underscores the importance of a holistic, integrated approach to dementia care and enables a wider range of

Table 1

Principles guiding comprehensive dementia care at home

- Delivery of high-value care

- Practices that are evidence-based and/or evidence informed.

- Seamless from time of diagnosis to end of life including bereavement

- Needs based (e.g., unmet needs, needs prioritized by families, and caregiver identified needs)

- Therapeutics, practices, strategies tailored to needs, values, beliefs, and practices of families

- Access to information, strategies, and therapeutics when needed and as needed

- Caregiver and person with dementia-centered care provision

- Purposeful engagement in decision making

- Considered as active members of the treatment team 
needs for the person with dementia and his/her caregiver to be identified and addressed including needs at a contextual and environmental level. This focus also includes the opportunity to assess and intervene on needs such as falland wander-risk management, challenging behaviors, medication administration and adherence, nutrition and hydration, and other home safety issues that may not be easily uncovered during a typical office-based outpatient primary care visit but which drive higher health care utilization and lower quality of life. Further, HBDC provides a framework for implementing a wider range of care strategies, interventions, and technologies, by providing improved wrap-around care for the person with dementia and the family using the home setting as a natural conduit.

There is growing evidence based on discrete and multicomponent interventions being developed for dementia care in the home setting - some of which are quite promising. These may focus solely on the person with dementia, the caregiver(s), the dyad, the environment, or multiple areas and can be delivered by a range of health care professionals or other skilled community workers. Interventions are diverse and include caregiver coping interventions or education; behavioral intervention such as customized activities, assistive technologies, and devices; web-based decision support tools; and care management or care coordination [36]. Interventions are delivered with in-home visits, telephone visits, virtual support groups, remote device monitoring, or combinations, sometimes paired with provider office visits. Collectively, these are being tested on a range of outcomes including mood, behavior, physical health, quality of life, nursing home placement, medication adherence, socialization, satisfaction with care, cost effectiveness, use of health services, caregiver burden, or caregiver mastery and coping. There is an emerging market for home-based "dementia-" or "Alzheimer's care," especially among managed care companies involved in long-term services and supports [2], home health care, or geriatric case management, as well as for technologies or devices for homes including those focused on safety and health monitoring. The quality and effectiveness of these products has not been clearly demonstrated.

HBDC offers an opportunity to bridge the continuum of long-term care services and supports (e.g., medical, personal, and social care) with other types of community supports (e.g., faith-based organizations) and informal social supports (e.g. neighbors, friends, and community members). Providers of care may include different professional providers, skilled community workers, or informal care contributors. Professional providers frequently involved in HBDC are social workers, home health nurses, home health aides, physical therapists, occupational therapists, and sometimes physicians, geriatric psychiatrists, podiatrists, or dentists who make house calls or provide services through telehealth.

Finally, focusing on HBDC provides a significant opportunity for cost and resource savings by reducing or delaying nursing home expenditures [37] and reducing acute care costs through interventions such as home safety efforts (e.g., decluttering a home to reduce fall risk, thereby avoiding hip fracture) that may reduce emergency department visits or inpatient stays.

In the sections below, we provide the Panel's summarization of key topic areas, opportunities and challenges of HBDC care: payment and care financing, workforce development, technology advances, and dissemination to stakeholders (e.g. patients, family caregivers, payers, providers, or insurers).

\section{Paying for dementia care at home}

"New payment models are needed to stimulate, reward, and support home care practices."

Dementia causes a significant and increasing financial burden on families and societies and costs that will grow exponentially over time. Worldwide costs for dementia totaled $\$ 818$ billion in 2015 US dollars and is expected to top 1 trillion (US dollars) by 2018. Forecasting models that account for increases in prevalence and increases in per capita costs suggest around a $6.5 \%$ per annum increase in total costs of care [38]. As one of the most expensive chronic conditions in the U.S. [32], total costs for all Americans with dementia was estimated at 259 billion in 2016, with $\$ 131$ billion (51\%) paid by Medicare, $\$ 44$ billion $(17 \%)$ by Medicaid, $\$ 56$ billion (22\%) out of pocket, and $\$ 28$ billion (11\%) from other sources; projections suggest annual spending will rise to $\$ 1.1$ trillion by 2050 [10] Average annual cost for Medicare beneficiaries with dementia are three times as higher $(\$ 23,497)$ compared to those without (\$7223) and an estimated 23 times higher for older Medicaid beneficiaries with dementia ( $\$ 8182$ ) compared to those without (\$349) [33]. There is substantial variation, however, in costs of caring for persons with dementia, and costs differ by care setting [37,39]. Cost of illness studies show that the average annual cost per patient totals $\$ 30,554$ and up to over $\$ 70,000$ involving mixed care setting, with nursing home care as a main cost driver $[37,40]$. Informal family members often provide financial support and unpaid time. An estimated 18.2 billion hours of unpaid care was provided in 2016, valued at \$230.1 billion in wages [3].

Cost financing for dementia is a considerable challenge. HBDC is rarely covered by Medicare and private insurers, and while Medicaid for low-income individuals funds some HBDC care, it reaches only a small percentage of those in need. Under the Community First Choice program established by the Affordable Care Act, for example, only eight states cover home-based care for Medicaid beneficiaries who would otherwise require nursing home care [41]. Most of the other state Medicaid programs cover homeand community-based services for low-income individuals with disabilities who would otherwise qualify for nursing home care under waivers, but these too reach only a portion of those in need because of waiting lists or restrictions on 
eligibility [41]. Innovative translation projects targeting home-dwelling Medicaid recipients with dementia are currently underway [42], which will hopefully support wider dissemination. Further, only one-fourth of the Medicare beneficiaries with physical and/or cognitive impairment are covered by Medicaid [43]. In limited situations, Medicare covers physician visits in a home setting or home health services by nurses following hospitalization and physical therapy services. However, most health and social care professionals trained in the care and support of persons with dementia and their family caregivers are not covered by Medicare.

The absence of insurance coverage for HBDC under Medicare is the "single largest obstacle" to the diffusion of innovative models of care for persons with dementia. In recent years, the Center for Medicare and Medicaid Services has funded testing such innovative models as Independence at Home, which pays for primary care physician services in the home, Hospital at Home, which provides services equivalent to inpatient hospital settings in the home for patients with select conditions, and models of care such as the Maximizing Independence at Home (MIND at Home) for persons with dementia [44-47].

Early evidence from these innovations suggest the potential for improvements in patient outcomes, functioning, and quality of life at a potentially lower cost, including reduced hospitalization and delayed or avoided long-stay nursing home institutionalization. There are some data from the Medicare Demonstration Project to suggest that it may be possible among certain beneficiary groups to spend more on home-based care than the cost of nursing home care [48] - further cost analyses are warranted to understand the potential for cost savings over the course of dementia. Earlier diagnosis of dementia by primary care practices could also yield important savings [49]. However, in general, there are few data examining the impact of these programs on cost saving specifically among persons with dementia.

Importantly, savings associated with the delivery of innovative models of care do not accrue to the organizations that incur the cost of providing the services. To realize a return, organizations providing such services need to contract with managed care plans such as Medicare Advantage Special Needs Plans or Medicaid managed care plans-but such organizations cover only a minority of those in need of HBDC and may be skeptical of savings, or anticipate reaping the savings without paying for the services. Further, they are unlikely to provide upfront assistance with capital costs or the costs of training qualified personnel.

Spreading innovative models of HBDC will require fundamental change in covered Centers for Medicaid and Medicare Services (CMS) benefits. A key determinant of success will be designing payment models that show promise of achieving better outcomes and lower acute and longterm care costs. Payment approaches that stimulate collaboration and integration of care across acute, residential, and long-term services and supports through shared savings need further policy development. This blending could be the evolution of Accountable Care Organizations (ACOs) into Integrated Care Organizations (ICOs) that take financial risk for long-term care costs as well as Medicare services, or could involve more modest steps such as Medicaid and/or Medicare payment of care management fees for services in the home and shared long-term care savings.

A recent policy proposal suggests one pragmatic way to begin to improve coverage for HBDC. Medicare Help at Home is a policy proposal to add a supplemental home and community-based services coverage option for Medicare beneficiaries [43]. A benefit of up to $\$ 400$ per week ( $\$ 20,800$ per year) is designed to cover up to 20 hours a week of personal care or equivalent cash benefit for other home and community-based care. Individuals enrolled in Medicare Help at Home would qualify for this benefit once they have developed serious physical and/or cognitive impairment. Beneficiaries who receive services all contribute toward their cost, ranging from $5 \%$ of cost for those with incomes below $150 \%$ of the federal poverty level (FPL) to $15 \%$ for those between 150-199\% of FPL, 25\% for those between 200-400\% of FPL, and 50\% for those above four times the poverty level. Based on the eligible population and assumptions about participation and utilization rates, it is estimated that the Medicare Help at Home benefit could be financed by monthly premiums of $\$ 33$ paid by all Medicare beneficiaries and an incremental payroll tax on employers and employees of $0.3 \%$ each.

The Medicare Help at Home proposal also contains provisions to improve care coordination and quality for beneficiaries. It gives beneficiaries the option of obtaining care from ICOs-an extension of the current ACOs. These organizations would be responsible for care coordination, support of family caregivers, and ensuring that an overall plan of care is developed and implemented based on patient and family preferences. ICOs would report on quality of care and how well they are able to meet patient and family preferences for care and continuing to live independently. They would have an incentive to adopt promising models of delivering services that reduce hospitalization and avoid or delay long-stay nursing home placement such as by providing physician and hospital services in the home and innovative models of care coordination.

The proposal would benefit Medicare beneficiaries who face the challenge of serious physical or cognitive functioning. It could improve access to home and community long-term services and supports, reduce the financial burden of out-of-pocket costs, assist family caregivers in providing support to maintain independent living longer, reduce health risks, and prevent avoidable hospitalization and emergency room use. Most of these benefits would be realized by the beneficiaries receiving services. However, if well designed, the benefit could also result in at least partially offsetting savings from reduced entry into Medicaid.

While we argue that HBDC will lead to cost savings overall, the care can require significant upfront outlay to 
implement effectively. Further, any shifts in the care paradigm to HBDC will need to be accompanied by explicit consideration of the informal caregiver so as not to place further financial and time burdens on already strained informal caregivers.

\section{Creating a skilled dementia care workforce}

"A skilled new workforce spanning long term care needs to be developed and equipped."

Another component needed to support HBDC in the future is the critical need for a well-trained and accessible workforce. To cope with the overwhelming, rising demand for dementia care, the healthcare system needs to move away from relying on the traditional physician-oriented approaches to health care and increasingly turn to home-based care options offered by nonmedical professionals. Several societal trends will amplify the need for more home-based care in the future, including the trend that individuals are living longer with multiple chronic conditions in a smaller family size [50], which is causing an increase in burden on what is sometimes referred to as the "sandwich" generation taking care of both their dependent children and parents. As a result, workforce issues need to be addressed in a swift, timely, and flexible manner. This section will highlight some of the major workforce issues and offer potential solutions for consideration by governments, medical and educational institutions, researchers, physicians, geriatricians, nurses, nurse practitioners, social workers, paraprofessionals, informal caregivers, and affected families.

Outpatient primary care serves as a hub of dementia care for most persons affected by dementias in the United States. While persons with dementia and their caregivers look primarily to their physicians and health care providers for support and guidance, in addition to diagnosis and treatment, few are actually equipped to provide such support. In fact, many care challenges are beyond the scope of most physicians both in terms of training as well as time and resources [51]. Thus, many caregivers find themselves navigating a loose network of dementia care supports that only increases the complexity of their role [13]. Further, because health care encounters are usually office-based, important care needs such as home safety and medication administration issues may not be readily assessed or observed. Improved care quality and well-prepared primary care providers will likely come from increased focus on primary care dementia education and coordination, as well as connection to and support from complementary community-based service providers who can share their expertise in addressing person with dementia and caregiver nonmedical care needs. For example, models of dementia care management in primary care for community-dwelling persons with dementia are being developed and tested in the United States and elsewhere, such as the UK, Netherlands, and Germany [52]. These collaborative care models are characterized by interprofessional teams and multicomponent interventions involving the persons with dementia and their caregivers.

There is a shortage in the United States, and globally, of health professionals to prepare for the growing health care demands of the aging population [53]. It is estimated by the WHO and World Bank that 40 million new health and social care jobs will be needed globally by 2030 (WHO, 2016). This shortage has contributed to severe access problems and quality of care for consumers, excessive provider costs due to continual recruitment and retraining, and extreme workloads and high injury rates for care providers [54]. A number of short-term and long-term issues have contributed to the current instability of the workforce that has hindered the ability to provide services in both facility- and home-based care including low wages and lack of benefits; lack of healthcare for many workers; poor working conditions with inadequate training and supervision that contributes to a high injury rate [54]; a high turnover in personnel that contributes to both a constant shortage of workers with training and to a high cost for providers as they constantly recruit replacements [55]; lack of adequate certification and specialized eldercare education programs and teachers [56]; lack of a workforce skills to adapt to new challenges in caring for an increasingly diverse and aging population with complex comorbidities [57-59]; and a disruption to affordable, safe, and personalized care for affected families. One of the common themes in global and national actions plans for addressing the dementia crisis is the need for an adequately trained workforce in all aspects of dementia care $[1,30,60,61]$. The availability of a skilled workforce is foundational to achieving other key objectives of these plans.

In achieving solutions, a balance must be struck between affordability of safe, high-quality care for families, and the pressing need to recruit, train, and retain the best workers to support the changing definition of what it means to be aging at home. There is a slowly simmering workforce crisis that will become increasingly dire as more of the baby boomer population becomes older than 65 years. The Panel identified several key areas of focus that begin to address the home-based care workforce crisis including elevating worker status and compensation, improving training and work conditions, and providing incentives and reimbursement changes to reward employers for creating a welltrained, skilled, and diverse workforce (Table 2).

\section{Opportunities for technology to support home-based dementia care}

"New technologies to promote best practices must be tested, integrated and deployed."

Technology can also play an important role in facilitating the success of patient-centered interventions, particularly in the home setting. While somewhat overlapping, dementia technologies can be divided into five general categories: (1) diagnostic/assessment; (2) monitoring; (3) assistive; 
Table 2

Key areas of focus for dementia competent workforce development

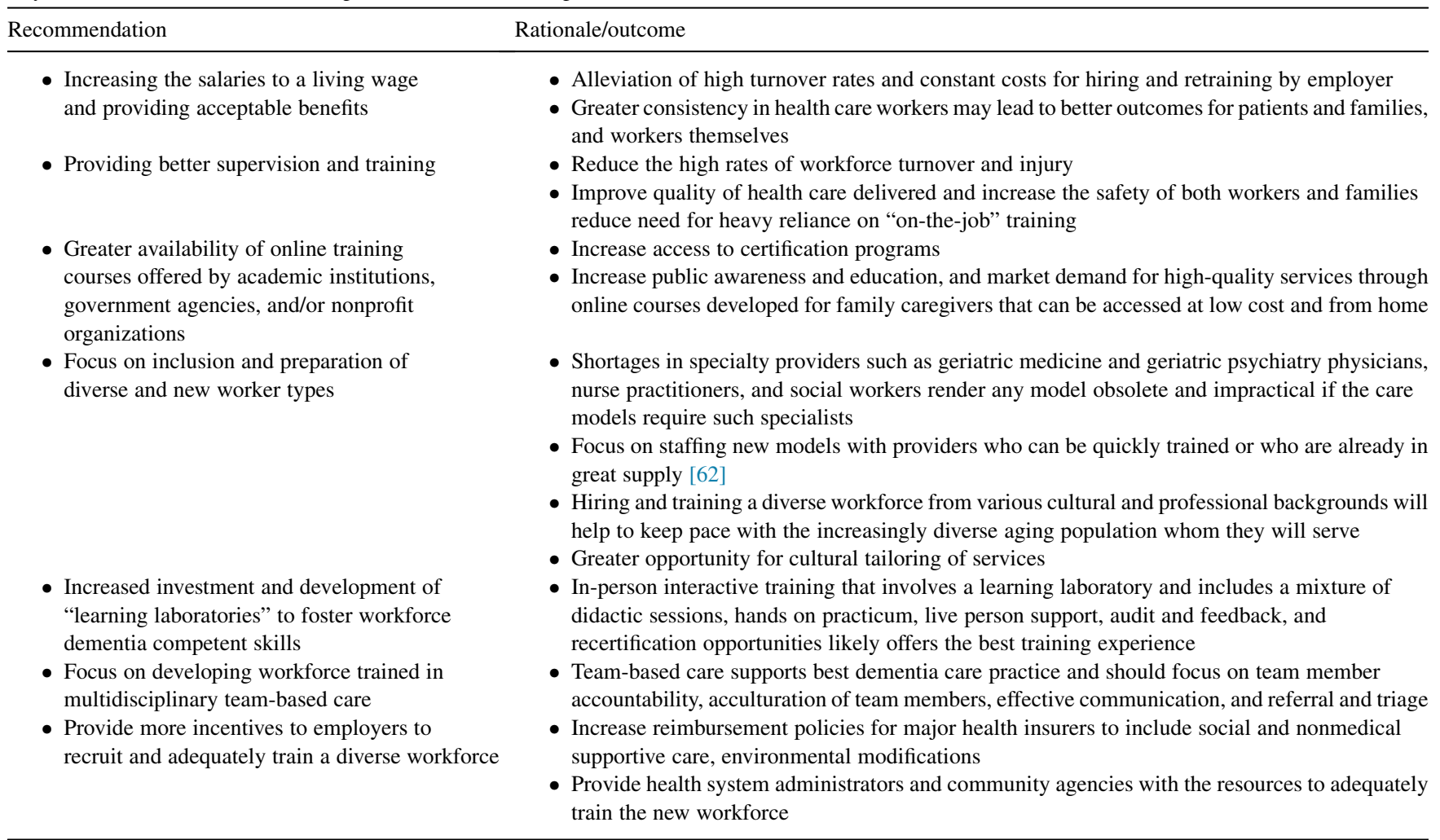

(4) therapeutic; and (5) caregiver supportive [63,64]. For example, in the home care setting, assessment technologies could be used to tailor individualized interventions and to provide specifics about the dose and timing of interventions delivered to individual participants. The latter knowledge can be used for program evaluation, as well as to learn what interventions are most successful for specific individuals. As another example, caregiver supportive technologies can provide web-based integrated inventories of resources available to persons with dementia and caregivers residing in homes. Such web-based links can help patients, families, and other caregivers access specific resources, for example, by setting up appointments, purchasing equipment, or communicating with the outside world.

Other forms of caregiver supportive technologies can also be used to identify, train, and monitor the formal and informal workforce that will deliver HBDC in the future. Novel multimedia training programs are being developed such as the WeCareAdvisor ${ }^{\mathrm{TM}}$ which is a web-based tool for caregivers of individuals living with dementia to assist them in the assessment and management of challenging behaviors [62]. With such caregiver training technologies, ongoing certifications can be administered, and quality control can be overseen. At the same time, technology can be used to access the workforce or potential workforce through marketing and other efforts.
Monitoring technologies such as wander management systems (e.g. bracelets or devices that alert if a boundary or threshold has been crossed) have been in use in residential care like assisted living settings for some time to improve safety and reduce elopement. Newer monitoring technologies are becoming available that can facilitate real-time interactions with persons with dementia and caregivers wherever they might be. This monitoring will consist of devices with specific characteristics, for examining monitoring vital signs, movement, ambulation, etc. It will allow direct communication between care management teams, clinicians, and others with persons with dementia and caregivers in the home. Real-time monitoring lays the foundation for real-time responses to crises or aberrant readings. The big challenge of this application of technology of course relates to confidentiality and privacy which will have to be closely guarded.

Finally, assistive technologies compensate for an individual's reduced abilities and will be clearly useful in keeping persons with dementia in the home setting. Examples include medication dispensers with timers and alarms to assist with adherence and reduce medication errors or technologies focusing on therapeutic aspects of care such as fostering engagement and activity (e.g. provide activities including videos, pictures, and games tailored to the person with dementia). 
Despite the potential for such technologies and an ever increasing number of products and devices coming onto the markets each day, very little evaluative data are available on the safety, use, effectiveness, costs, and unintended consequences of such available technology for HBDC, representing a substantial knowledge gap [65]. Further, it is questionable how well current product development is informed by persons with dementia and their caregivers and the daily life experiences, or perceived useful these products in dementia care at home [66]. These are important gaps in knowledge that should be addressed to better understand the potential impact of technology in supporting HBDC.

\section{Translational challenges for disseminating home- based dementia care}

"More effective development of value, understanding of competing local priorities and adaption, and improved communication about home-based care are needed."

Home-based models of care represent an important departure from the current organization of health care services paradigm for older adults with dementia, and we have already highlighted a number of opportunities and challenges to this shift including financing, workforce issues, and technology. There are several additional key challenges in moving home-based models of care from the narrow realm of research to the widespread and diverse communities across the nation.

First, there is the perceived value of dementia interventions. Researchers develop and test best practice models of dementia care in research studies, which are typically characterized by small groups of highly selected and homogenous groups of patients receiving interventions in wellcontrolled settings [67-70]. Translation to the "messiness" of real-world practice settings often dilutes impact, and policy makers and payers often view results from these controlled settings as a best case scenario. Thus, the true value, in the eyes of payers and policy makers, may be questionable. Also, policy makers and payers often have unique needs and goals and attach different values to the costs and benefits of an intervention than researchers, patients, or families. When the value of a new model of care remains controversial or debatable in the eyes of health system decision-makers (or insurance benefits administrators), diffusion remains limited. For example, many payers have not or are just beginning to develop a clear understanding of the significant impact of dementia on resource use and service intensity among their patient populations - so they may not yet be able to fully appreciate the potential return on investment for adoption of dementia interventions. Further, to the extent that value is defined as cost savings, new models of care that offer additional medical and nonmedical services, which are needed for dementia care, to already underserved populations will be disadvantaged. Likewise, to the extent that value is defined by decreased mortality, decreased functional impairment, or cure, new models of care focusing on progressive illnesses like dementia will be disadvantaged. Finally, the perception of demand for new dementia care models from the consumer base is still low. Dementia is a highly stigmatized condition with a misperception that "nothing can be done." The needs and care requirements for persons with dementia and their family caregivers too often remain hidden to the system until a serious crisis emerges. For this reason, early efforts at improving implementation and dissemination may include activation of market demand through the activation of advocacy groups and patient families and more effective communication about the need, benefits, and value of HBDC to the public and other stakeholders [71].

Competing priorities for policy-makers and payers is another challenge to diffusion of new models of care. Given that populations of older adults suffer from multimorbidity and thus present competing priorities for care, interventions that offer the most benefit to the many may outweigh other options. New models of home-based care may also compete for space and resources within geographic areas and availability of skilled care providers within the structure of health systems for resources for programming or staffing (e.g. ACOs) or for support within the technical infrastructure of a health system (e.g. electronic health records).

Adaption of interventions to specific contexts represents another barrier [71-73]. Organizations usually cannot simply take an intervention "off-the-shelf" and directly apply it to their local settings. Intense staff training or certification requirements; lengthy assessments; settings, differences in staffing types and environmental resources; patient population case-mix differences; financing; and regional, local, and organizational culture all present complexities that may make translation impractical or even impossible in some settings. Further, attempts to adapt intervention to local contexts may risk changing the intervention so much so that it no longer represents the original evidencebased model, possibly rendering the intervention ineffective. At an individual level, adaptation and tailoring of interventions to persons with dementia and their caregivers (the dyad) are unique and a key feature of HBDC. Models of care may need to adapt to cultural, ethnic, or racial diversity, low health literacy, low income, or family dynamics within the setting of an individual home. At the federal level, models may need to adapt to changing regulations, changing quality criteria, and changing payment models. Implementation teams sometimes adapt by embedding the intervention within a local priority that is already moving forward, coupling their intervention with common comorbid conditions or by engaging local champions to enable and encourage the change in practice.

\section{Summary}

HBDC represents a promising person-centered and potentially cost efficient paradigm shift. Given uncertainties about 
Table 3

BrightFocus panel core recommendations

Core recommendations
New models of long-term care and support that centers around the home as
the nexus of care from diagnosis to end of life, integrating medical,
social, emotional, environmental and supportive care must be prioritized
for dementia into the future.
New payment models to support effective evidence-based home care
practices and that stimulate and reward integration of care across acute
and long-term services and supports needs further development and
testing and policy reform.
Development and preparation of a dementia competent workforce to offer a
range of home-based care services is critically needed and could be
supported by addressing key issues related to employee retention
including increasing salaries, better supervision, more flexible,
continuous and engaging training, creation of "credentialing" for skilled
workers along with pathways for promotion, team-based care, and
rewarding high-quality care.
New and existing technologies to link families to care providers and share
information more efficiently, monitor and promote home safety, monitor
health and symptoms status, and deliver care strategies; care management
and treatments must be fully evaluated and tested, deployed, and utilized.
To address barriers to dissemination of home-based dementia care including
absence of a coherent national approach to payment for home-based care,
cultural factors, and lack of understanding of the long-term value of
home-based dementia care, a major priority of the field should be
considering perceived value, variations in local priorities and resources,
and adaptation to promote greater and more effective communication
about the need and benefits of home-based dementia care must to
stakeholders.

"curative" treatment for Alzheimer's and related dementias, the likelihood that the number of persons living with dementia requiring care will exceed current projections, and there is a national imperative to improve the ability to look after per living with dementia and support their caregivers in community-based homes for as long as possible, with dignity and good life quality. Evidence supports the premise that HBDC can be structured in ways that are systematic and that it can produce quality clinical outcomes. Early research suggests that HBDC is also cost effective and could potentially be supported through cost offsets seen by reducing utilization of higher levels of care such as nursing homes, emergency departments, and acute hospitals. The cost offset potential across settings and types of care are particularly promising in an era of ACOs and ICOs, which have greater incentives to reduce costs across the care continuum, but this must be confirmed through further data-driven evaluation. There is also the need to consider and examine the potential risks and unintended consequences (e.g. increasing caregiver personal and financial burden, increasing out-ofpocket costs for care, confidentiality and privacy with technology use, safety and reduced quality of care by poorly trained providers) of the paradigm shift to HBDC.

We therefore put forth a set of key consensus recommendations. As detailed in Table 3, the panel strongly believes and advocates for the home to be considered as the nexus of care. In this context, new payment models are needed to support home care practices and reward integration of care, and a diverse new workforce that spans long-term care services and supports should be developed and prepared urgently. Further, the home provides a prime opportunity for the testing, integration, and deployment of new technologies to promote communication, monitoring and safety, and symptoms management. Finally, it is clear that dissemination of homebased care practices will not happen easily-it must be supported by intervention development and testing stages, by explicitly considering perceived value from key stakeholders, variations in local priorities and resources, and clear communication and dissemination of research results and value propositions to stakeholders about the need and benefits of HBDC promote demand and uptake of evidence-based dementia services. These recommendations provide a framework to chart a course forward for setting specific targets and timelines and will hopefully guide the National Alzheimer's Plan Project and development of local and national Alzheimer's plans. In conclusion, as new models of person- and family-centered dementia care paradigms emerge, now is the time to rethink how the home can serve as the nexus of care for addressing medical, social, emotional, and cultural needs.

\section{Acknowledgments}

We wish to acknowledge Elizabeth Tracey (scientific writer) for assistance in project organization and in preparing this consensus panel report.

This work was supported by the BrightFocus Foundation (Grant\# CA2016637), National Institutes of Health (Grant \#R01AG046274), and Centers for Medicare and Medicaid (Grant\# 1C1CMS331332).

\section{RESEARCH IN CONTEXT}

1. Systematic review: Strategic planning at local, national, and global levels is underway to address the dementia crisis.

2. Interpretation: This paper presents findings and recommendations of a national multidisciplinary expert panel focused on the importance, opportunities, and barriers related to shifting the clinical practice paradigm to focus on home-based dementia care.

3. Future directions: Among a host of issues, these plans must consider a wide range of issues: treatment development and research; timely diagnosis; care delivery, health system design, and service financing; quality of care and consumer preferences; workforce development; and public education and awareness. 


\section{References}

[1] Prince M, Wimo A, Guerchet M, Gemma-Claire A, Wu YT, Prina M. World Alzheimer Report 2015: The Global Impact of Dementia-An Analysis of Prevalence, Incidence, Cost and Trends. London: Alzheimer's Disease International; 2015:84

[2] AARP. 2015 Report: Caregiving in the U.S. Available at: http://www. aarp.org/content/dam/aarp/ppi/2015/caregiving-in-the-united-states2015-report-revised.pdf. Accessed June 9, 2017.

[3] Wolff J, Spillman B, Freedman V. A national profile of family and unpaid caregivers who assist older adults with health care activities. JAMA Intern 2016. Available at: http://jamanetwork.com/journals/ jamainternalmedicine/fullarticle/2491683. Accessed April 27, 2017.

[4] Statistics NC for H. Long-term care providers and services users in the United States: Data from the National Study of Long-Term Care Providers Library of Congress Cataloging-in-Publication Data. Vital Health Stat 2016;3:2016-1422. http://lccn.loc.gov/2016000580. Accessed September 12, 2017.

[5] Zimmerman S, Sloane PD, Reed D. Dementia prevalence and care in assisted living. Health Aff (Millwood) 2014;33:658-66.

[6] Seitz D, Purandare N, Conn D. Prevalence of psychiatric disorders among older adults in long-term care homes: a systematic review. Int Psychogeriatr 2017;22:1025-39.

[7] Callahan CM, Boustani M, Sachs GA, Hendrie HC. Integrating care for older adults with cognitive impairment. Curr Alzheimer Res 2009;6:368-74.

[8] Miller EA, Weissert WG. Predicting elderly people's risk for nursing home placement, hospitalization, functional impairment, and mortality: a synthesis. Med Care Res Rev 2000;57:259-97.

[9] Phelan EA, Borson S, Grothaus L, Balch S, Larson EB. Association of incident dementia with hospitalizations. JAMA 2012;307:165.

[10] Alzheimer's Association. 2017 Alzheimer's disease facts and figures. Alzheimers Dement 2017;13:325-73.

[11] Callahan CM, Sachs GA, Lamantia MA, Unroe KT, Arling G, Boustani MA. Redesigning systems of care for older adults with Alzheimer's disease. Health Aff (Millwood) 2014;33:626-32.

[12] Miranda-Castillo C, Woods B, Galboda K, Oomman S, Olojugba C, Orrell M. Unmet needs, quality of life and support networks of people with dementia living at home. Health Qual Life Outcomes 2010;8:132.

[13] Black BS, Johnston D, Rabins PV, Morrison A, Lyketsos C, Samus QM. Unmet needs of community-residing persons with dementia and their informal caregivers: Findings from the maximizing independence at home study. J Am Geriatr Soc 2013;61:2087-95.

[14] Jennings LA, Reuben DB, Evertson LC, Serrano KS, Ercoli L, Grill J, et al. Unmet needs of caregivers of individuals referred to a dementia care program. J Am Geriatr Soc 2015;63:282-9.

[15] Miranda-Castillo C, Woods B, Orrell M. People with dementia living alone: what are their needs and what kind of support are they receiving? Int Psychogeriatr 2010;22:607-17.

[16] Hodgson NA, Black BS, Johnston D, Lyketsos CG, Samus QM. Comparison of unmet care needs across the dementia trajectory findings from the MIND at home study. J Geriatr Palliat Care 2014;2:5.

[17] Cohen-Mansfield J, Dakheel-Ali M, Marx MS, Thein K, Regier NG. Which unmet needs contribute to behavior problems in persons with advanced dementia? Psychiatry Res 2015;228:59-64.

[18] Gitlin NL, Hodgson N, Piersol Verrier C, Hess E, Hauck WW. Correlates of quality of life for individuals with dementia living at home: The role of home environment, caregiver, and patient-related characteristics. Am J Geriatr Psychiatry 2014;22:587-97.

[19] Gaugler JE, Kane RL, Kane RA, Newcomer R. Unmet care needs and key outcomes in dementia. J Am Geriatr Soc 2005; 53:2098-105.

[20] Hughes TB, Black BS, Albert M, et al. Correlates of objective and subjective measures of caregiver burden among dementia caregivers: influence of unmet patient and caregiver dementia-related care needs. Int Psychogeriatr 2014;26:1875-83.

[21] Eska K, Graessel E, Donath C, Schwarzkopf L, Lauterberg J, Holle R. Predictors of institutionalization of dementia patients in mild and moderate stages: a 4-year prospective analysis. Dement Geriatr Cogn Dis Extra 2013;3:426-45.

[22] Hébert R, Dubois MF, Wolfson C, Chambers L, Cohen C. Factors associated with long-term institutionalization of older people with dementia: data from the Canadian Study of Health and Aging. J Gerontol A Biol Sci Med Sci 2001;56:M693-9.

[23] Gaugler JE, Leach CR, Clay T, Newcomer RC. Predictors of nursing home placement in African Americans with dementia. J Am Geriatr Soc 2004;52:445-52.

[24] Barney KF, Perkinson MA. Occupational Therapy with Aging Adults: Promoting Quality of Life through Collaborative Practice.

[25] Gitlin LN, Winter L, Dennis MP, Hodgson N, Hauck WW. A biobehavioral home-based intervention and the well-being of patients with dementia and their caregivers. JAMA 2010;304:983.

[26] Gitlin LN, Hodgson NA, Choi SSW. Home-based interventions targeting persons with dementia: What is the evidence and where do we go from here? In: Dementia Care. Cham: Springer International Publishing; 2016. p. 167-88.

[27] Samus Q, Johnston D, Hess E, Morrison A. Efficacy of a multidimensional home-based care coordination intervention for elders with memory disorders: The Maximizing Independence at Home (MIND at Home). Alzheimers Dement 2012;8:S780.

[28] Callahan CM, Boustani MA, Unverzagt FW, Austrom MG, Damush TM, Perkins AJ, et al. Effectiveness of collaborative care for older adults with Alzheimer disease in primary care: a randomized controlled trial. JAMA 2006;295:2148-57.

[29] Committee AGSCP. AGS Clinical Practice Committee. Guidelines abstracted from the American Academy of Neurology's Dementia Guidelines for Early Detection, Diagnosis, and Management of Dementia. J Am Geriatr Soc 2003;51:869-73.

[30] WHO. Development of a Draft Global Action Plan on the Public Health Response to Dementia. WHO, 2017. Available at: http:// www.who.int/mental_health/neurology/dementia/action_plan_consul tation/en. Accessed June 9, 2017.

[31] Keenan TA. Home and Community Preferences of the 45+ Population Data Collected by GfK Custom Research North America Report Prepared. Available at: https://assets.aarp.org/rgcenter/general/home-com munity-services-10.pdf. Accessed September 12, 2017.

[32] Hurd MD, Martorell P, Delavande A, Mullen KJ, Langa KM. Monetary costs of dementia in the United States. N Engl J Med 2013; 14368:1326-34.

[33] Alzheimer, Association. Costs of Alzheimer's to Medicare and Medicaid. Available at: http://act.alz.org/site/DocServer/2012_Costs_ Fact_Sheet_version_2.pdf?docID=7161. Accessed April 27, 2017.

[34] Olsen C, Pedersen I, Bergland A, et al. Differences in quality of life in home- dwelling persons and nursing home residents with dementia-a cross-sectional study. BMG Geriatr 2016;16:137.

[35] Kaye HS. Gradual rebalancing of Medicaid long-term services and supports saves money and serves more people, statistical model shows. Health Aff (Millwood) 2012;31:1195-203.

[36] Gitlin LN, Marx K, Stanley IH, Hodgson N. Translating evidencebased dementia caregiving interventions into practice: state-of-thescience and next steps. Gerontologist 2015;55:210-26.

[37] Schaller S, Mauskopf J, Kriza C, Wahlster P, Kolominsky-Rabas PL. The main cost drivers in dementia: a systematic review. Int J Geriatr Psychiatry 2015;30:111-29.

[38] Wimo A, Guerchet M, Ali GC, et al. The worldwide costs of dementia 2015 and comparisons with 2010. Alzheimers Dement 2017; 13:1-7.

[39] Handels RL, Wolfs CA, Aalten P, Verhey FR, Severens JL. Determinants of care costs of patients with dementia or cognitive impairment. Alzheimer Dis Assoc Disord 2013;27:30-6. 
[40] Kelley AS, McGarry K, Gorges R, et al. The burden of health care costs for patients with dementia in the last 5 years of life. Ann Intern Med 2015;163:729.

[41] Burwell SM. Community First Choice: Final Report to Congress. Available at: https://www.medicaid.gov/medicaid/hcbs/downloads/ cfc-final-report-to-congress.pdf. Accessed June 9, 2017.

[42] Fortinsky RH, Gitlin LN, Pizzi LT, et al. Translation of the care of persons with dementia in their environments (COPE) intervention in a publicly-funded home care context: Rationale and research design. Contemp Clin Trials 2016;49:155-65.

[43] Davis K, Willink A, Schoen C. Medicare help at home. Available at: http://healthaffairs.org/blog/2016/04/13/medicare-help-at-home. Accessed June 9, 2017.

[44] CMS. Affordable Care Act Payment Model Saves More than \$25 Million in First Performance Year. Available at: https://www.cms. gov/Newsroom/MediaReleaseDatabase/Press-releases/2015-Press-rel eases-items/2015-06-18.html. Accessed June 9, 2017.

[45] Caplan GA, Sulaiman NS, Mangin DA, Aimonino Ricauda N, Wilson AD, Barclay L. A meta-analysis of "hospital in the home". Med J Aust 2012;197:512-9.

[46] Leff B, Burton L, Mader SL, et al. Hospital at home: feasibility and outcomes of a program to provide hospital-level care at home for acutely ill older patients. Ann Intern Med 2005;143:798.

[47] Samus QM, Johnston D, Black BS, Hess E, Lyman C, Vavilikolanu A, et al. A multidimensional home-based care coordination intervention for elders with memory disorders: The maximizing independence at home (MIND) pilot randomized trial. Am J Geriatr Psychiatry 2014; 22:398-414.

[48] Fox P, Newcomer R, Yordi C, Arnsberger P. Lessons learned from the Medicare Alzheimer disease demonstration. Alzheimer Dis Assoc Disord 2000;14:87-93.

[49] Davis K, Willink A, Amjad H. What is the potential for improving care and lowering cost for persons with dementia? Int Psychogeriatr 2016; 28:357-8

[50] Beard JR, Officer A, de Carvalho IA, et al. The world report on ageing and health: a policy framework for healthy ageing. Lancet 2016; 387:2145-54.

[51] Sivananthan SN, McGrail KM. Diagnosis and disruption: populationlevel analysis identifying points of care at which transitions are highest for people with dementia and factors that contribute to them. J Am Geriatr Soc 2016;64:569-77.

[52] Dreier-Wolfgramm A, Michalowsky B, Austrom MG, et al. Dementia care management in primary care. Z Gerontol Geriatr 2017;50:68-77.

[53] Crisp N, Chen L. Global supply of health professionals. N Engl J Med 2014;370:950-7.

[54] American Association of Homes \& Services for the Aging and the Institute for the Future of Aging Services. The Long-term Care Workforce: Can the Crisis be Fixed? Problems, Causes and Options. Available at: http://www.leadingage.org/sites/default/files/LTC_Workforce_ Commission_Report.pdf. Accessed June 9, 2017.

[55] Bragg E, Hansen JC. A revelation of numbers: Will America's eldercare workforce be ready to care for an aging America? Generations 2010;34:11.

[56] Maiden RJ, Horowitz BP, Howe JL. Workforce training and education gaps in gerontology and geriatrics: what we found in New York state. Gerontol Geriatr Educ 2010;31:328-48.
[57] WHO. Preparing a Health Care Workforce for the 21st Century: The Challenge of Chronic Conditions. WHO, 2013. Available at: http:// www.who.int/chp/knowledge/publications/workforce_report/en. Accessed June 9, 2017.

[58] Costley AW. Exploring skills-based competencies through geriatric care management modules. Gerontol Geriatr Educ 2016;37:329-41.

[59] Nancarrow SA, Moran AM, Graham I. Preparing a 21st century workforce: is it time to consider clinically based, competency-based training of health practitioners? Aust Health Rev 2014;38:115-7.

[60] Tsaroucha A, Benbow SM, Kingston P, Le Mesurier N. Dementia skills for all: a core competency framework for the workforce in the United Kingdom. Dementia 2013;12:29-44.

[61] Rosow K, Holzapfel A, Karlawish JH, Baumgart M, Bain LJ, Khachaturian AS. Countrywide strategic plans on Alzheimer's disease: developing the framework for the international battle against Alzheimer's disease. Alzheimers Dement 2011;7:615-21.

[62] Kales HC, Gitlin LN, Stanislawski B, et al. WeCareAdvisor ${ }^{\text {TM}}$ : The development of a caregiver-focused, web-based program to assess and manage behavioral and psychological symptoms of dementia. Alzheimer Dis Assoc Disord 2017;31:263-70.

[63] Bossen A, Kim H, Steinhoff A, Strieker M, Williams K. Emerging roles for telemedicine and smart technologies in dementia care. Smart Homecare Technol Telehealth 2015;3:49-57.

[64] Bharucha AJ, Anand V, Forlizzi J, Dew MA, Reynolds CF, Stevens S, et al. Intelligent assistive technology applications to dementia care: current capabilities, limitations, and future challenges. Am J Geriatr Psychiatry 2009;17:88-104.

[65] Dawson A, Bowes A, Kelly F, Velzke K, Ward R. Evidence of what works to support and sustain care at home for people with dementia: a literature review with a systematic approach. BMC Geriatr 2015;15:59.

[66] Mao HF, Chang LH, Yao G, Chen WY, Huang WN. Indicators of perceived useful dementia care assistive technology: Caregivers' perspectives. Geriatr Gerontol Int 2015;15:1049-57.

[67] Brodaty H, Arasaratnam C. Meta-analysis of nonpharmacological interventions for neuropsychiatric symptoms of dementia. Am J Psychiatry 2012;169:946-53.

[68] McLaren AN, Lamantia MA, Callahan CM. Systematic review of nonpharmacologic interventions to delay functional decline in community-dwelling patients with dementia. Aging Ment Health $2013 ; 17: 655-66$

[69] Olazarn J, Reisberg B, Clare L, et al. Nonpharmacological Therapies in Alzheimer's disease: A systematic review of efficacy. Dement Geriatr Cogn Disord 2010;30:161-78.

[70] Reilly S, Miranda-Castillo C, Malouf R, Hoe J, Toot S, Challis D, et al. Case management approaches to home support for people with dementia. In: Reilly S, ed. Cochrane Database of Systematic Reviews, Vol 1. Chichester, UK: John Wiley \& Sons, Ltd; 2015:CD008345

[71] Boustani MA, Munger S, Gulati R, Vogel M, Beck RA, Callahan CM. Selecting a change and evaluating its impact on the performance of a complex adaptive health care delivery system. Clin Interv Aging 2010; 5:141-8.

[72] Crabtree BF, Nutting PA, Miller WL, et al. Primary care practice transformation is hard work: insights from a 15-year developmental program of research. Med Care 2011;49:S28-35.

[73] Litaker D, Tomolo A, Liberatore V, Stange KC, Aron D. Using complexity theory to build interventions that improve health care delivery in primary care. J Gen Intern Med 2006;21 Suppl 2:S30-4. 